\title{
Intestinal graft-versus-host disease
}

\author{
Sabah Servaes
}

Received: 10 August 2010 /Accepted: 3 September 2010 /Published online: 2 October 2010

(C) Springer-Verlag 2010

A 17-month-old boy with acute lymphoblastic leukemia status 61 days post cord blood transplant presented with vomiting, diarrhea and feeding intolerance. Fluoroscopic examination with barium demonstrates diffuse narrowing of the small bowel lumen referred to as toothpaste- or ribbon-like (Fig. 1) and consistent with graft-versus-host disease (GVHD). Despite improvement of intestinal GVHD with immunosuppressive therapy, the boy developed respiratory failure and infection and died 4 months later.

GVHD typically affects the skin, intestine and liver because of alloreactive donor $\mathrm{T}$ cells [1]. The diagnosis is typically made based on clinical findings. Radiological studies are not specific, but bowel wall thickening can be observed because of edema [2]. Steroids are the first-line therapy.

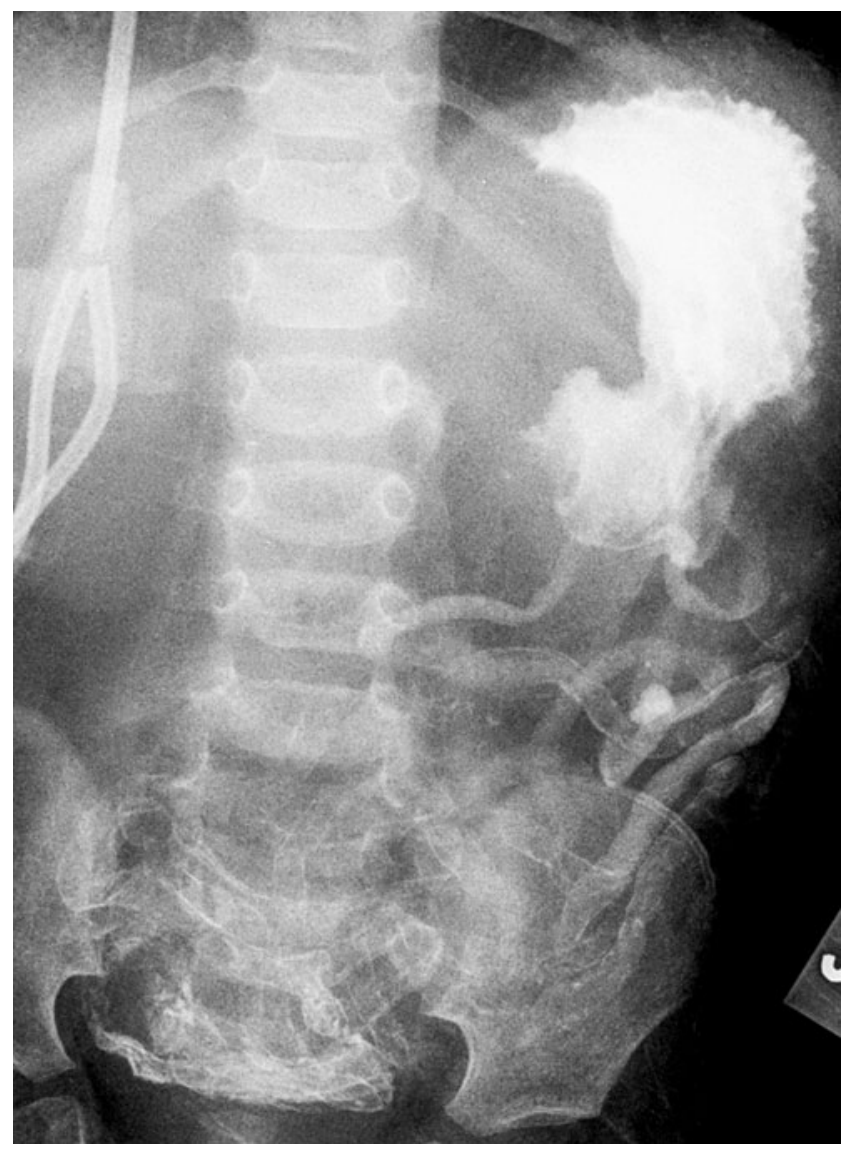

Fig. 1 Fluoroscopic image

\section{References}

1. Washington K, Jagasia M (2009) Pathology of graft-versus-host disease in the gastrointestinal tract. Hum Pathol 40:909-917

2. Day DL, Carpenter BL (1993) Abdominal complications in pediatric bone marrow transplant recipients. Radiographics 13:1101-1112 